\title{
Особенности селективного роста наноколонн GaN на профилированных подложках $c$-сапфира различной геометрии
}

\author{
() А.Н. Семенов, Д.В. Нечаев, С.И. Трошков, А.В. Нащекин, П.Н. Брунков, В.Н. Жмерик, С.В. Иванов \\ Физико-технический институт им. А.Ф. Иофрфе Российской академии наук, \\ 194021 Санкт-Петербург, Россия \\ E-mail: semenov@beam.ioffe.ru
}

(Получена 17 апреля 2018 г. Принята к печати 25 апреля 2018 г.)

\begin{abstract}
Исследованы особенности роста наноколонн $\mathrm{GaN}$ на профилированных подложках $c$-сапфира с регулярным массивом микроконусов, имеющих различные плотность и диаметр основания в диапазонах $(1-5) \cdot 10^{7} \mathrm{~cm}^{-2}$ и 2.5-3.5 мкм соответственно. Изучена кинетика и определены режимы селективного роста одиночных наноколонн $\mathrm{GaN}$ с диаметром 30-100 нм на вершинах микроконусов при радикально меньших скоростях роста на их боковых гранях. Исследовано влияние геометрии микроконусов, температуры подложки, шероховатости исходной поверхности и присутствия индия в качестве сурфактанта на степень селективности роста.
\end{abstract}

DOI: $10.21883 /$ FTP.2018.13.46884.8894

\section{1. Введение}

В последнее время для изготовления различных светоизлучающих диодов на основе соединений $\mathrm{A}^{\mathrm{III}} \mathrm{N}$ все большее распространение получают профилированные подложки сапфира (ППС), в частности с высокой плотностью микроконусов (МК) $\left(\sim 10^{7} \mathrm{~cm}^{-2}\right)$, имеющие практически ту же стоимость, что и стандартные полированные подложки $c$-сапфира. В результате было налажено их коммерческое производство с различными геометрическими размерами и различной плотностью МК [1]. Необходимо отметить, что ППС могут использоваться не только в классических приборных гетеростуктурах на основе $\mathrm{GaN}$, где их положительный эффект связан со снижением концентраций протяженных дефектов и оптимизацией вывода излучения. Недавно нами была показана возможность использования ППС в процессах плазменно-активированной молекулярно-пучковой эпитаксии (ПА МПЭ) для селективного роста упорядоченных массивов микрорезонаторов на основе InN и $\mathrm{GaN}[2,3]$, а также наноколонн (НК) на основе $\mathrm{GaN}$ [4]. Последние объекты, для которых характерна радикально (более чем на порядок величины) сниженная плотность по сравнению с традиционными наномасочными технологиями НК [5], интересны для создания оптически изолированных эффективных источников одиночных фотонов на основе $\mathrm{HK} \mathrm{InGaN} / \mathrm{GaN}$, работающих вплоть до комнатной температуры [6].

Использование ППС для селективного роста выгодно отличается от обычно используемых дорогостоящих и низкопроизводительных технологий формирования диэлектрических или металлических наномасок с помощью электронной литографии, сфокусированных ионных пучков, нанопечати (nanoimprinting) с разрешением на уровне 100 нм [5] также еще и тем, что может быть легко адаптировано к большим площадям.

В прошлых наших исследованиях была показана возможность пространственно-селективного роста азотполярных НК $\mathrm{GaN}(000 \overline{1})$ на ППС и была представлена качественная модель, описывающая такой рост с учетом особенностей термодинамики (поверхностной энергии) и поверхностной подвижности адатомов на различных полярных и полуполярных кристаллографических плоскостях, присутствующих на поверхности ППС [4]. В настоящей работе описываются особенности роста НК $\mathrm{GaN}(000 \overline{1})$ на ППС с различной геометрией конусов и исследуется влияние на селективность роста на таких подложках химического состава зародышевых слоев, шероховатости их поверхности и наличия сурфактантов.

\section{2. Эксперимент}

Исследуемые НК выращивались на установке ПА МПЭ Compact 21T (Riber) с использованием ППС двух типов: A, аналогичных использованным в [4], и В, которые отличались в первую очередь углом при вершине. Для подложек А-типа (В-типа) он составлял $120^{\circ}\left(100^{\circ}\right)$ соответственно. Кроме того, различались и плотности МК на подложках А и $\mathrm{B}$, которые составляли $10^{7}$ и $5 \cdot 10^{7} \mathrm{~cm}^{-2}$ соответственно. В ряде случаев также использовались подложки типа А с усеченными (плоскими) вершинами МК.

Подложки отжигались при температуре $T_{S}=820^{\circ} \mathrm{C}$ и нитридизовались при температуре $780^{\circ} \mathrm{C}$ в потоке активированного азота $0.44 \mathrm{ML} / \mathrm{c}$ (в единицах скорости роста $\mathrm{GaN}, \mathrm{ML}$ - монослой). Далее с помощью эпитаксии с повышенной миграцией в условиях обогащения $\mathrm{A}^{\mathrm{III}}$ выращивались два типа зародышевых слоев: GaN (AlN) при отношениях потоков элементов $\mathrm{A}^{\mathrm{III}} / \mathrm{N} \sim 2(1.3)$ и температурах подложки $700-760^{\circ} \mathrm{C}\left(760^{\circ} \mathrm{C}\right)$ с использованием потоков галлия (алюминия) и азота 1.0 (0.6) и $0.44 \mathrm{ML} / \mathrm{c}$ соответственно. Номинальные толщины обоих зародышевых слоев составляли 65 нм. Для дальнейшего роста $\mathrm{HK} \mathrm{GaN}$ использовались условия обогащения азотом при соотношении потоков $\mathrm{Ga} / \mathrm{N}=0.2$ (поток $\mathrm{Ga} 0.09 \mathrm{ML} / \mathrm{c}$ ). Температура роста варьировалась в диапазоне $T_{S}=740-780^{\circ} \mathrm{C}$. В некоторых процессах 

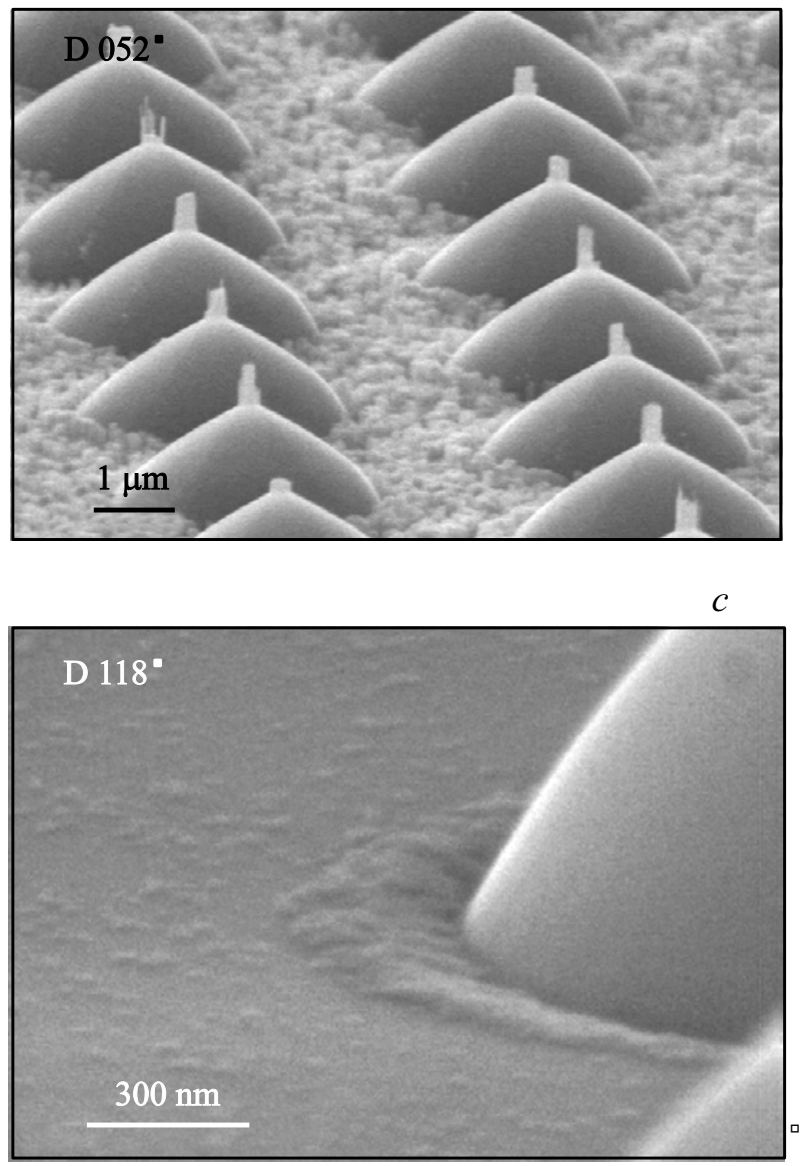

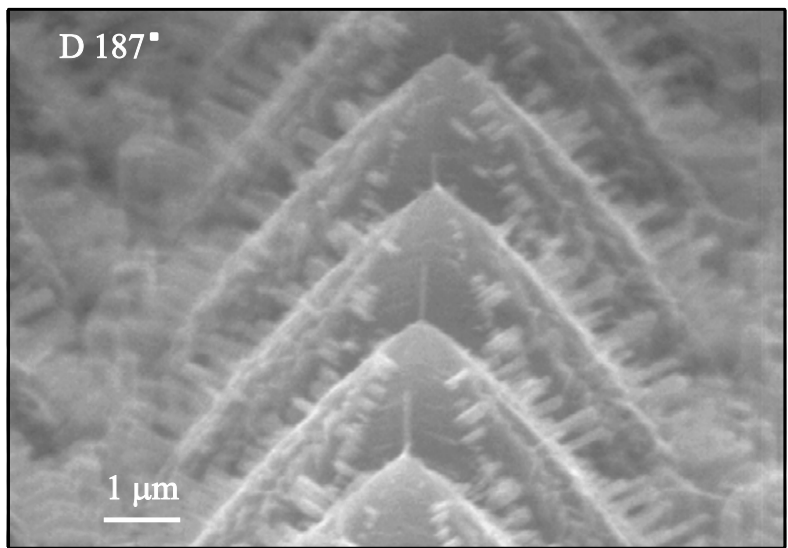

$d$

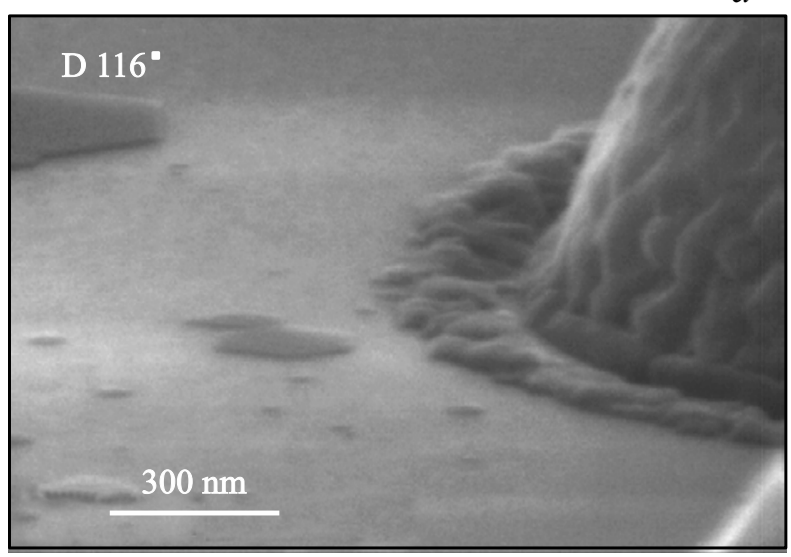

Рис. 1. РЭМ-изображения поверхности ППС: $a$ - тип А с усеченными МК и сформированными на них ансамблями НК; $b$ - тип В, невысокая селективность роста НК $\mathrm{GaN}$ при тех же ростовых условиях (отношение потоков $\mathrm{Ga} / \mathrm{N}=0.2, T_{S}=760^{\circ} \mathrm{C}$ ) и без использования затравочного слоя, как и в случае $a . c, d-$ РЭМ-изображения основания МК на ППС типа А с неусеченными МК после выращивания зародышевого слоя $\mathrm{GaN}$ в условиях обогащения $\mathrm{Ga}$ при $T_{S}=760(c)$ и $700^{\circ} \mathrm{C}(d)$.

для увеличения длины диффузии адатомов галлия дополнительно к ростовым потокам добавлялся поток индия различной интенсивности $0.4-1 \mathrm{ML} / \mathrm{c}$. Следует отметить, что при используемых температурах роста НК GaN встраивание In в твердую фазу невозможно, т. е. In в данном случае использовался как сурфактант с целью увеличения поверхностной подвижности атомов $\mathrm{Ga}$ и $\mathrm{N}$.

Выращенные наноструктуры изучались методами растровой электронной микроскопии (РЭМ) (CamScan 4-88-DV-100, Великобритания; JMS-7001F JEOL, Япония) и атомно-силовой микроскопии (АСМ) (Dimension 3100 Veeco, CША). Для топографических исследований поверхности методом АСМ в полуконтактном режиме использовались зонды RTESP (Bruker, Германия) с радиусом закругления острия 10 нм.

\section{3. Результаты и обсуждение}

Как известно уже довольно давно, использование условий роста с сильным обогащением азотом приводит к интенсивному спонтанному росту $\mathrm{HK}$ GaN в отсутствие каких-либо металлических (Au) катализаторов [7]. Согласно модели роста, предложенной нами для профилированных подложек [4], основным механизмом роста НК является быстрая восходящая и нисходящая диффузия адатомов галлия по полуполярным склонам МК, занимающих бо́льшую часть поверхности подложки, и их последующее встраивание в плоскости, характеризующиеся минимальной поверхностной энергией. В случае используемых в данной работе ППС это N-полярные плоскости $(000 \overline{1})$, т.е. вершины МК, а впоследствии плоские вершины НК и пространство между МК. Согласно полученным в настоящей работе данным, температура роста $760^{\circ} \mathrm{C}$ оказывается достаточной для эффективного подавления роста $\mathrm{HK} \mathrm{GaN}$ на склонах МК на подложках типа А. Даже если не предпринимать специальных усилий по формированию зародышевого слоя, в случае использовании подложек типа А с усеченными конусами при температуре роста $760^{\circ} \mathrm{C}$ наблюдается достаточно высокая селективность роста (рис. 1,a). Однако сами НК на вершинах усеченных МК растут не одиночными, а ансамблями по 
$a$

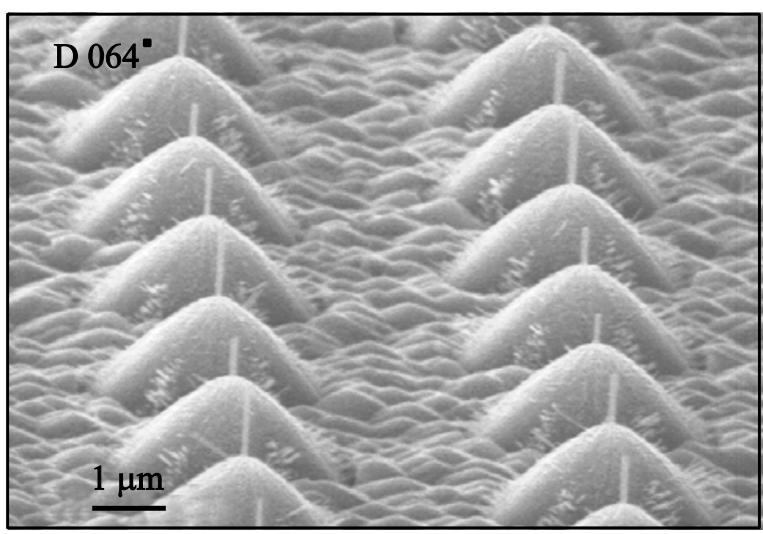

$c$

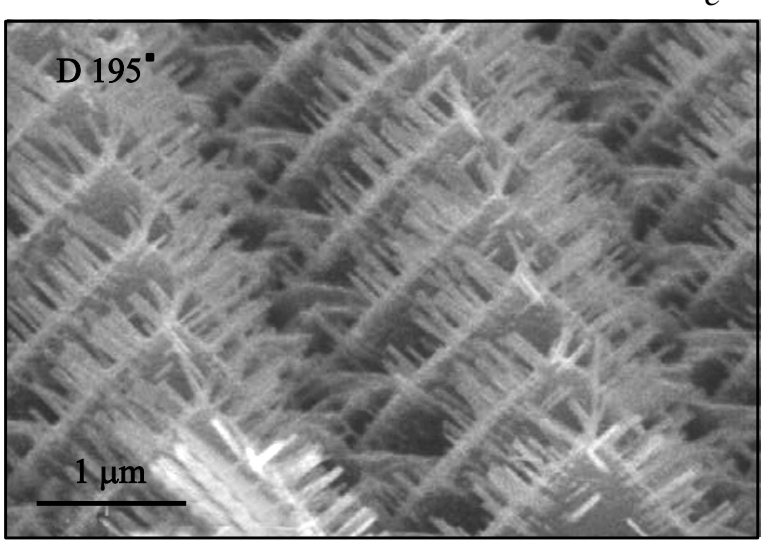

$b$

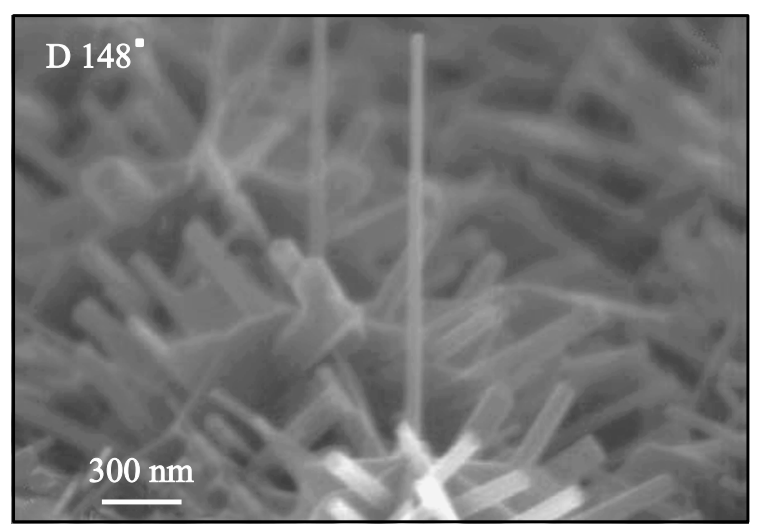

$d$

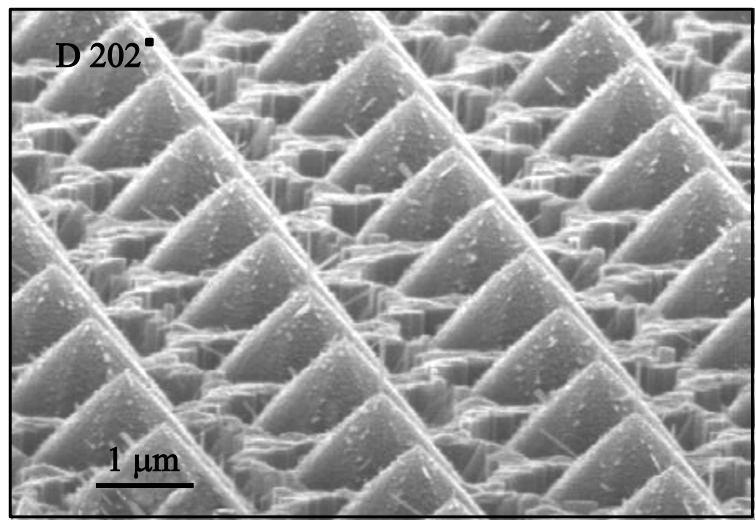

Рис. 2. $a-$ РЭМ-изображение поверхности ППС типа А с селективным ростом НК $\mathrm{GaN}$ на высокотемпературном затравочном слое $\mathrm{GaN} .(b-d)-$ PЭМ-изображения поверхности ППС типа В с выращенными НК $\mathrm{GaN}: b-$ стандартные условия, $T_{S}=760^{\circ} \mathrm{C}$, как в случае $a ; c-T_{S}=760^{\circ} \mathrm{C}$, использование потока $\operatorname{In}(0.4 \mathrm{ML} / \mathrm{c})$ в качестве сурфактанта; $d-T_{S}=770-780^{\circ} \mathrm{C}$, использование потока In $(0.8-1 \mathrm{ML} / \mathrm{c})$ в качестве сурфактанта, более высокая селективность роста НK GaN.

5-10 штук. Диаметр таких образований составляет 200-300 нм. В случае использования подложек типа А с неусеченными МК и особенно типа В с более остроконечными МК, по всей видимости, скорость диффузии оказывается уже недостаточной для эффективного транспорта адатомов Ga до вершины МК. К тому же несколько меняется и кристаллографическая ориентация полуполярных плоскостей на склонах МК. Это приводит к зарождению и росту НК на склонах, что особенно заметно проявляется в случае использования подложек типа В, которые характеризуются также большей высотой МК (рис. 1,b). Повысить степень селективности роста в данном случае оказалось возможным за счет оптимизации режима роста зародышевого слоя $\mathrm{GaN}$.

На рис. $1, c$ и $d$ приведены изображения зародышевых слоев $\mathrm{GaN}$, выращенных на ППС типа А в условиях обогащения $\mathrm{Ga}$, но при различных температурах. В случае выращивания зародышевого слоя $\mathrm{GaN}$ при температуре $760^{\circ} \mathrm{C}$ поверхность МК остается гладкой, в то время как на поверхностях $(000 \overline{1})$, т. е. между МК и на их вершинах, наблюдается заметный рост GaN. Важно отметить, что при этом вокруг самого МК наблюдается микроканавка, образование которой, как мы полагаем, связано с эффективным транспортом адатомов $\mathrm{Ga}$ по боковым граням МК, как к его основанию, так и к вершине, и существенно более медленным распределением адатомов по поверхности $(000 \overline{1})$, что и стимулирует локальное увеличение скорости роста $\mathrm{GaN}$ вокруг основания МК. Принципиально иная картина наблюдается при выращивании зародышевого слоя при температуре $700^{\circ} \mathrm{C}$. По всей видимости, данная температура уже недостаточна для эффективного транспорта адатомов $\mathrm{Ga}$ по полуполярным склонам МК, вследствие чего наблюдается рост GaN как между МК, так и на их боковых поверхностях. При этом заметно возрастают размер шероховатости стенок МК и глубина канавки при основании.

Среднеквадратическая шероховатость, определенная на основании исследований поверхности с использованием $\mathrm{ACM}$, составляет величину $\mathrm{RMS}=0.14$ нм для исходной подложки, при этом использование высокотемпературного буфера $\mathrm{GaN}\left(T_{S}=760^{\circ} \mathrm{C}\right)$ не приводит к заметному изменению этого значения, величина RMS сохранилась на уровне 0.14 нм. Использование же в 
качестве зародышевого слоя AlN или низкотемпературного слоя $\mathrm{GaN}\left(T_{S}=700^{\circ} \mathrm{C}\right)$ приводит к заметному развитию шероховатостей поверхности, и значение RMS возрастает почти в 40 раз $(\mathrm{RMS}=3.1 \mathrm{HM})$.

По всей видимости, температура $760^{\circ} \mathrm{C}$ является слишком низкой для роста $\mathrm{AlN}$ (аналогично $T_{S}=700^{\circ} \mathrm{C}$ для роста $\mathrm{GaN}$ ), когда подвижность атомов элементов III группы крайне мала, что способствует зарождению множественных островков роста и развитию шероховатости. Наличие шероховатостей в свою очередь в значительной степени затрудняет транспорт адатомов $\mathrm{Ga}$ по склонам MC во время роста $\mathrm{HK} \mathrm{GaN}$ и приводит к спонтанному зарождению и росту НК по всей поверхности МК. Более того, использование низкотемпературных зародышевых слоев $\mathrm{GaN}\left(T_{S}=700^{\circ} \mathrm{C}\right)$ или $\mathrm{AlN}$ $\left(T_{S}=760^{\circ} \mathrm{C}\right)$ приводит к заметно более низкой степени селективности роста по сравнению с использованием ППС без каких-либо зародышевых слоев. Плотность $\mathrm{HK} \mathrm{GaN}$ на боковых поверхностях МК, выращенных на неоптимальном зародышевом слое, существенно выше по сравнению с ростом наноколонок без каких-либо зародышевых слоев (см. рис. $1, b)$.

В случае высокотемпературного роста зародышевого слоя $\mathrm{GaN}\left(T_{S}=760^{\circ} \mathrm{C}\right)$ на ППС типа А оказалось возможным достичь высокой степени селективности формирования НК и в заметной степени подавить их рост на боковых поверхностях МК. Типичный диаметр НК GaN, выращенных на вершинах МК, в этом случае составил 50-80 нм (рис. 2,a). Однако в случае использования ППС типа В наблюдалась заметно более низкая степень селективности роста НК при использовании высокотемпературного зародышевого слоя $\mathrm{GaN}$ (рис. 2, b). Даже дальнейшее повышение температуры подложки во время роста $\mathrm{HK} \mathrm{GaN}$ до $T_{S}=780^{\circ} \mathrm{C}$ не позволило подавить формирование роста НК на боковых гранях МК. Более того, оно привело к резкому снижению скорости роста на вершинах МК вследствие десорбции Ga и разложения $\mathrm{GaN}$, что послужило причиной снижения высоты, диаметра и плотности НК в 10 и более раз. По всей видимости, изменение кристаллографии граней МК из-за более острого угла при вершине, а также большая высота самих МК в значительной степени осложняют диффузию адатомов, что приводит к зарождению и дальнейшему росту НК на ребрах и плоскостях граней МК.

Поскольку повышение $T_{S}$, а также оптимизация зародышевого слоя в случае ППС типа В не привела к повышению селективности роста, в данной работе для стимуляции диффузии галлия по поверхности был использован индий в качестве сурфактанта. Как было показано ранее, использование индия во время роста $\mathrm{HK} \mathrm{GaN}$ на стандартных непрофилированных подложках сапфира заметно увеличивает диффузию галлия по поверхности (0001), тем самым подавляя двумерный рост и способствуя росту НК $\mathrm{GaN}[8]$. При использовании ППС, когда стоит задача повышения селективности роста НК на вершинах МК, увеличение длины диффузии является ключевым фактором.
Как и ожидалось, использование потока индия $0.4 \mathrm{ML} / \mathrm{c}$ позволило заметно простимулировать рост НК, однако при температурах роста до $T_{S}=760^{\circ} \mathrm{C}$ селективность роста не увеличивалась. При этом скорость роста НК на склонах МК была сопоставима со скоростью роста на вершинах (рис. 2, c). Однако более высокой селективности роста на ППС типа В удалось добиться лишь за счет увеличения температуры роста до $770-780^{\circ} \mathrm{C}$ и добавления индия на уровне $0.8-1 \mathrm{ML} / \mathrm{c}$. Как показано на рис. $2, d$, при использовании таких режимов плотность НК на боковых склонах МК снижается, а сами эти боковые НК характеризуются бо́льшим диаметром и меньшей длиной по сравнению с НК, формирующимися на вершинах МК, диаметр которых варьируется в диапазоне 30-40 нм при высоте 300-600 нм. Насколько нам известно, такое значение диаметра является минимальным для НК $\mathrm{GaN}$, выращенных за счет самоорганизации, т. е. без применения нанолитографических масок.

\section{4. Заключение}

В данной работе показана возможность реализации селективного на большой площади роста наноколонок $\mathrm{GaN}$ методом ПА МПЭ на ППС с различной геометрией МК без использования технологий формирования наномасок. Обнаружено, что на диффузию галлия по поверхности МК в значительной степени оказывают влияние три основных фактора: шероховатость исходной поверхности, которая в существенной степени определяется типом и режимом роста зародышевого слоя, температура роста и присутствие потока сурфактанта (индия). Выявлены и экспериментально апробированы условия, позволяющие воспроизводимо получать одиночные НК $\mathrm{GaN}$ с диаметром в диапазоне 30-100 нм на вершинах МК ППС при существенном подавлении роста НК на склонах МК.

Работа выполнялась при поддержке проекта РНФ (№ 14-22-00107). АСМ- и частично РЭМ-исследования выполнены с использованием оборудования федерального ЦКП „Материаловедение и диагностика в передовых технологиях“, поддержанного Министерством образования и науки России (уникальный идентификатор проекта RFMEFI62117X0018).

\section{Список литературы}

[1] Yu-Chung Chena, Bo-Wen Lina, Wen-Ching Hsuc, Yew-Chung Sermon Wua. Mater. Lett., 118, 72 (2014).

[2] T.V. Shubina, V.N. Jmerik, V.Yu. Davydov, D.R Kazanov, A.N. Smirnov, D.V. Nechaev, N. Kuznetsova, G. Pozina, C. Hemmingsson, S.V. Ivanov. Physica Status Solidi B, 253, 845 (2016).

[3] T.V. Shubina, G. Pozina, V.N. Jmerik, V.Yu. Davydov, C. Hemmingsson, A.V. Andrianov, D.R. Kazanov, S.V. Ivanov. Sci. Rep., 5, 17970 (2015).

[4] V.N. Jmerik, N.V. Kuznetsova, D.V. Nechaev, T.V. Shubina, D.A. Kirilenko, S.I. Troshkov, V.Yu. Davydov, A.N. Smirnov, S.V. Ivanov. J. Cryst. Growth, 477, 207 (2017). 
[5] K. Kishino, H. Sekiguchi, A. Kikuchi. J. Cryst. Growth, 311, 2063 (2009).

[6] M.J. Holmes, K. Choi, S. Kako, M. Arita, Y. Arakawa. Nano Lett., 14, 982 (2014).

[7] S. Fernández-Garrido, J. Grandal, E. Calleja, M.A. SánchezGarcía, D. Lópocez-Romero. J. Appl. Phys., 106, 126102 (2009).

[8] O. Landré, R. Songmuang, J. Renard, E. Bellet-Amalric, H. Renevier, B. Daudin. Appl. Phys. Lett., 93, 183109 (2008).

Редактор В.В. Шаронова

\section{The selective area growth of GaN nanocolumns on patterned sapphire substrates with different geometry}

A.N. Semenov, D.V. Nechaev, S.I. Troshkov, A.V. Nashchekin, P.N. Brunkov, V.N. Jmerik, S.V. Ivanov loffe Institute, 194021 St. Petersburg, Russia

Abstract The growth peculiarities of $\mathrm{GaN}$ nanocolumns (NCs) on patterned sapphire substrates with regular microcone array having different density and base diameter in the range of $(1-5) \cdot 10^{7} \mathrm{~cm}^{-2}$ and $2.5-3.5 \mu \mathrm{m}$, respectively, were investigated. The growth kinetic was studied and the growth regimes were found which allowed to achieve the selective growth of single GaN NCs with diameters of $30-100 \mathrm{~nm}$ on tops of the microcones with the dramatically low growth rate on other cone planes. The influence of microcone geometry, substrate temperature, surface roughness and indium atoms as surfactant on the growth selectivity were studied in detail. 